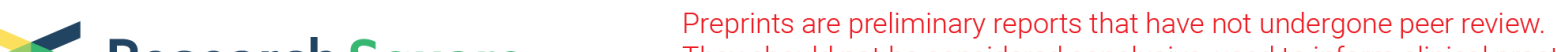 $\begin{array}{ll}\text { Research Square } & \text { They should not be considered conclusive, used to inform clinical practice, } \\ \text { or referenced by the media as validated information. }\end{array}$
}

\section{A Multifaceted Clinical Decision Support Intervention to Improve Adherence to Thromboprophylaxis Guidelines}

Tessa Jaspers ( $\nabla$ t.jaspers@etz.nl)

Elisabeth-TweeSteden Ziekenhuis https://orcid.org/0000-0002-3939-1403

Marjolijn Duisenberg-van Essenberg

Elisabeth-TweeSteden Ziekenhuis

Barbara Maat

Elisabeth-TweeSteden Ziekenhuis

Marc Durian

Elisabeth-TweeSteden Ziekenhuis

Roy van den Berg

Elisabeth-TweeSteden Ziekenhuis

Patricia van den Bemt

University Medical Centre Groningen

\section{Research Article}

Keywords: Decision Support Systems, Clinical, Guideline Adherence, Venous Thromboembolism, Electronic Health Records, Heparin, Low-Molecular-Weight

Posted Date: February 11th, 2021

DOI: https://doi.org/10.21203/rs.3.rs-214868/v1

License: (c) (1) This work is licensed under a Creative Commons Attribution 4.0 International License.

Read Full License

Version of Record: A version of this preprint was published at International Journal of Clinical Pharmacy on March 11th, 2021. See the published version at https://doi.org/10.1007/s11096-021-01254-x. 


\section{Abstract}

Background: Venous thromboembolism is a potentially fatal complication of hospitalisation, affecting approximately $3 \%$ of non-surgical patients. Administration of low molecular weight heparins to the appropriate patients adequately decreases venous thromboembolism incidence, but guideline adherence is notoriously low.

Objective: To determine the effect of a multifaceted intervention on thromboprophylaxis guideline adherence. The secondary objective was to study the effect on guideline adherence specifically in patients with a high venous thromboembolism risk. As an exploratory objective, we determined how many venous thromboembolisms may be prevented.

Setting: A Dutch general teaching hospital.

Method: A prospective study with a pre- and post-intervention measurement was conducted. A multifaceted intervention, consisting of Clinical Decision Support software, a mobile phone application, monitoring of duplicate anticoagulants and training, was implemented. Guideline adherence was assessed by calculating the Padua prediction and Improve bleeding score for each patient. The number of preventable venous thromboembolisms was calculated using the incidences of venous thromboembolism in patients with and without adequate thromboprophylaxis and extrapolated to the annual number of admitted patients.

Main outcome measure: Adherence to thromboprophylaxis guidelines in pre-and post-intervention measurements.

Results: 170 patients were included: 85 in both control and intervention group. The intervention significantly increased guideline adherence from $49.4 \%$ to $82.4 \%$ (OR $4.78 ; 95 \% \mathrm{Cl}$ 2.37-9.63). Guideline adherence in the patient group with a high venous thromboembolism risk also increased significantly from $54.5 \%$ to $84.3 \%$ (OR $2.46 ; 95 \% \mathrm{Cl} 1.31-4.62)$, resulting in the potential prevention of \pm 261 venous thromboembolisms per year.

Conclusions: Our multifaceted intervention significantly increased thromboprophylaxis guideline adherence.

\section{Impact On Practice Statements}

- Our multifaceted intervention significantly increases overall guideline adherence from $49.4 \%$ to $82.4 \%$

- Implementing this multifaceted intervention globally may prevent almost half of all venous thromboembolisms in non-surgical patients

- We advocate the use of highly specific and user-friendly clinical decision support to address similar problems in healthcare 


\section{Introduction}

Approximately $3 \%$ of in-hospital non-surgical patients develop a venous thromboembolism (VTE) without adequate prophylaxis [1]. This rises to $11 \%$ in patients that have a higher VTE risk. VTEs are complications with a high morbidity and mortality. Around $40 \%$ of VTEs are pulmonary embolisms, which is one of the most common causes of death in hospitals worldwide [2-4]. Correct usage of thromboprophylaxis can reduce the incidence of VTEs in high risk patients by approximately $80 \%$ [1]. On the other hand, thromboprophylaxis increases bleeding risk, with a potential morbidity and mortality as well. Adequate use of thromboprophylaxis is therefore an important factor in patient safety and quality of healthcare.

Advice on when to prescribe thromboprophylaxis has been included in various international guidelines, such as The American College of Chest Physicians (ACCP) guideline thrombosis prophylaxis 2012 and the Dutch Internists Association (NIV) guideline anti-thrombotic policy $2015[5,6]$. Both guidelines are similar as to when to prophylaxis should be started as they both use the same risk assessment models (RAMs): the Padua prediction score for VTE risk and the Improve bleeding matrix for bleeding risk [1,5-7].

According to these guidelines, thromboprophylaxis, preferably in the form of low molecular weight heparins (LMWHs), should be started if a patient has a high risk of VTE. If the patient also has a bleeding risk, mechanical prophylaxis in the form of elastic stockings or intermittent pneumatic compression should be started $[5,6]$.

However, low adherence to thromboprophylaxis guidelines is described in literature. An international cross-sectional study from 32 countries stated that, on average, $39.5 \%$ of non-surgical patients with a high VTE risk received adequate prophylaxis [8]. The Netherlands Institute for Research of Healthcare (NIVEL) reported that in 13 Dutch hospitals an average of $60 \%$ of non-surgical patients with a high VTE risk received thromboprophylaxis [9]. In addition; $37 \%$ of patients with an increased bleeding risk, without a high VTE risk, received thromboprophylaxis. In the patient group with an increased bleeding risk and a high VTE risk, $60 \%$ of patients received chemical thromboprophylaxis instead of mechanical prophylaxis.

In 2013 en 2018, the Cochrane Collaboration published a systematic review about several methods that may increase guideline adherence of thromboprophylaxis in non-surgical patients [10,11]. Single interventions with training, posters and/or pocket cards demonstrated as ineffective in improving guideline adherence [10,12-15]. Multifaceted interventions resulted in a mean improvement of only $4 \%$ $[11,16,17]$. Randomized controlled trials with computer based alerts demonstrated an improvement of 0 $16 \%$ in guideline adherence, with the use of non-specific alerts $[11,18,19]$. Results from single-arm studies with Clinical Decision Support (CDS) also demonstrated substantial heterogeneity, with improvements rates of $0-23 \%$ [20-23]. The CDS used in these studies were also non-specific, such as continuous flashing reminders when thromboprophylaxis had not been started, posing a high risk of alert fatigue [18,20-23].

To our knowledge, no study has described the effect of a multifaceted intervention with a highly specific CDS. Therefore, we aimed to implement a multifaceted intervention with a user-friendly CDS and highly 
specific design. To achieve this level of specificity, the Padua Prediction Score was built into the Electronic Health Record (EHR), making it possible to alert only if relevant.

\section{AIM OF THE STUDY}

The aim of this study was to determine the effect of a multifaceted intervention, consisting of a highly specific CDS, training, a mobile phone application and monitoring on duplicate anticoagulant medication by a pharmacist, on guideline adherence in non-surgical patients. The secondary objective was to study the effect of the multifaceted intervention on guideline adherence in patients with a high VTE risk ( $\geq 4$ points on the Padua prediction score). Exploratory objective was to calculate how many VTEs may be prevented annually in our hospital by implementing the multifaceted intervention.

\section{ETHICS APPROVAL}

A waiver was obtained from the institutional review board Brabant as the study was not within the scope of the Dutch Human Research Act (NW2019-26).

\section{Methods}

\section{Study design and setting}

This study was a prospective intervention study with a pre- and post-intervention measurement. It was conducted at the Elisabeth TweeSteden Hospital (ETZ), a large general teaching hospital and traumacenter with 996 beds in Tilburg, The Netherlands.

\section{Study population}

Non-surgical patients, $\geq 18$ years of age, admitted to the departments of neurology, internal medicine or oncology \& haematology, with a hospital stay of $\geq 36$ hours in the pre- or post-intervention period have been included. Patients with orders for comfort measures only have been excluded.

\section{Multifaceted intervention}

Before the introduction of the multifaceted intervention, the initiation of thromboprophylaxis was left to the discretion of the physician, who could consult locally available web based protocols and (inter)national guidelines on thromboprophylaxis.

The multifaceted intervention was implemented from November 2018 through February 2020 and consisted of the following components: the introduction of a mobile phone application 'Pocket Cards' (Interactive Studios, Rosmalen, The Netherlands), a clinical rule 'duplicate anticoagulant medication', CDS in the form of a Best Practice Advisory (BPA) in the Electronic Health Record (EHR, Epic ${ }^{\circledR}$, Epic Systems, Verona, USA) and training of prescribers as described in table 1. 


\section{Outcome measures}

The primary outcome was the proportion of patients for whom thromboprophylaxis was prescribed according to guidelines. The secondary outcome was to determine the effect of the intervention on guideline adherence specifically in patients with a high VTE risk.

Guideline adherence was assessed using the Padua Prediction Score and Improve bleeding RAM, as included in table 2. [1,7]. The VTE risk was considered high at a Padua Prediction score of $\geq 4$ [1]. The bleeding risk was considered high at an Improve score of $\geq 7$, or when a patient scored positive on the high-risk factors: prior bleeding in the last 3 months, an active gastro-duodenal ulcer or a platelet count $<50 \times 10^{9} / \mathrm{L}$ [7]. According to (inter)national guidelines, chemical thromboprophylaxis should be initiated if a patient has a high risk of VTE. If the patient also has an increased bleeding risk, mechanical prophylaxis in the form of elastic stockings or intermittent pneumatic compression should be started $[5,6]$.

The exploratory outcome was to calculate how many VTEs may theoretically be prevented annually in the ETZ by the multifaceted intervention. Therefore, the annual number of patients admitted to the ETZ with a high VTE risk and no bleeding risk was calculated. To this end, an annual admission rate of 25,000 patients and a prevalence of $39.7 \%$ patients with a high VTE risk without bleeding risk was used, resulting in 9,925 patients [1]. Subsequently, the expected number of VTEs in the pre-intervention (T0) and postintervention (T1) period was calculated based on the percentages of correctly and incorrectly treated patients with a high VTE risk. A VTE incidence rate of $2.2 \%$ was used in the patient group with thromboprophylaxis and $11.0 \%$ in the patient group without thromboprophylaxis. Finally the expected number of preventable VTEs was calculated as the difference between T0 and T1 [1].

\section{Data collection}

Assessment of guideline adherence was done once for each patient between $\geq 36$ hours and $\leq 60$ hours after admission by one pharmacist (TJ). When in doubt, a hematologist (MD) was consulted. Preintervention data collection was performed retrospectively over one month (T0, October 2018). Postintervention data collection was performed prospectively over one month (T1, March 2020).

In both periods, a patient list was generated from the EHR with all patients who met the inclusion criteria. For each patient, risk factors included in the Padua Prediction Score and Improve bleeding RAM were collected from the patient's EHR.

Patient characteristics and drug use were mostly discrete data in the EHR (e.g. values from prepopulated lists, coded data or data entered into fields requiring specific alphanumeric formats). However, it is possible that not all risk factors for VTE and bleeding were documented as discrete data. To collect the non-discrete data, every risk factor was searched for manually in the free text notes in the patient's EHR. 


\section{Data monitoring}

Patient data were coded and processed in Datamanager 5.43.0 (The research manager, Deventer, The Netherlands).

\section{Data analysis}

The sample size was calculated using a p-value of $0.05,80 \%$ power, a $60 \%$ rate of guideline adherence prior to the multifaceted intervention, and an expected increase of $20 \%$ in adequacy following the multifaceted intervention [8-10]. A Chi-square test calculation resulted in 81 patients per group. In order to ensure the required sample size, we increased the number of patients to 85 per group, thus 170 patients in total.

Data analysis was performed with IBM SPSS Statistics vs 24 (IBM, New York, USA). Categorical variables were presented as proportions (in \%) and continuous variables were presented as mean (with standard deviation) if the data were normally distributed or with a median (with an interquartile range) if the data were not normally distributed. Differences in patient characteristics between groups were tested using Pearson $X^{2}$ test for categorical variables, or Fisher's exact test when the expected number of cases per cell was $\leq 5$. Unpaired t-tests were used for continuous variables. The Mann-Whitney $\mathrm{U}$ test was used when variables were not parametric.

The difference in the percentage of correctly treated patients between $\mathrm{T} 0$ and $\mathrm{T} 1$ was analyzed by univariate logistic regression. Common confounding variables such as age and sex and the highest scoring VTE risk factors in the Padua prediction score (immobility, malignancy and VTE in the past) were included in the multivariate logistic regression $[1,24]$. Moreover, length of stay was chosen as a confounding variable as this may influence the initiation of thromboprophylaxis. The admission department was chosen as this varied the most $(p=0.17)$ between the two groups. Covariates were chosen according to the Stepwise regression with backward elimination, with a cut-off $p$-value $<0.2$ for covariate selection. Covariates immobility, malignancy and VTE in the past were included in the final model.

Results were presented as odds ratios (OR) with $95 \%$ confidence intervals $(95 \% \mathrm{Cl})$. All statistics were 2tailed, and $p<0.05$ was considered to be statistically significant.

\section{Results}

172 patients were reviewed, 85 in T0 and 87 in T1. None of the patients in T0 were excluded, while two patients were excluded in $\mathrm{T} 1$ because of a comfort measures only policy. In total, 170 patients were included; 85 in both T0 and T1.

Table 3 summarizes the patient characteristics. There are no significant differences between the two patient groups. In both groups, the mean age was 66 years and men represented a small majority. The 
median length of stay was 8.3 days in T0 and 7.4 days in T1. A high VTE risk was present in $76.5 \%$ and $70.6 \%$ in T0 and T1 ( $p=0.39)$, respectively. A high bleeding risk was present in $15.3 \%$ and $14.1 \%$ in T0 and $\mathrm{T} 1(\mathrm{p}=0.83)$, respectively.

\section{Overall guideline adherence}

The percentage of patients in whom thromboprophylaxis was prescribed adherent to guidelines is shown in table 4. The adherence was 49.4\% in T0 and 82.4\% in T1 (OR 4.78; 95\% Cl 2.37-9.63) and increases after adjustment for immobility, malignancy and VTE in the past (OR adj 5.88; 95\% Cl 2.74-12.62). Both a significant increase in patients who correctly received thromboprophylaxis and in patients who correctly did not receive thromboprophylaxis was observed.

\section{Guideline adherence in high risk VTE patients}

There were 55 patients with a high VTE risk, without a bleeding risk in T0. This is comparable to 51 patients in T1. Guideline adherence in this patient group increased significantly from $54.5 \%$ to $84.3 \%$ (OR $2.46 ; 95 \% \mathrm{Cl} 1.31-4.62)$ in $\mathrm{T} 1$ compared to T0. This effect was larger when adjusted for immobility, malignancy and VTE in the past $\left(\mathrm{OR}_{\mathrm{adj}} 4.00 ; 95 \% \mathrm{Cl} 1.86-8.59\right)$.

\section{Number of VTEs that may be prevented}

The number of venous thromboembolisms in T0 and T1 extrapolated to the annual number of admitted patients in the ETZ, is shown in figure 1. Considering an annual admission rate of 25,000 patients, 9,925 (39.7\%) patients will have a high VTE risk, without a bleeding risk [1]. In T0, guideline adherence was $54.5 \% ; 5,409$ of 9,925 patients with a high VTE risk would have received thromboprophylaxis adequately. Of these patients approximately 119 (2.2\%) would develop a VTE. Non-guideline adherence was 45.5\%; 4,516 patients with a high VTE risk would not have been treated with thromboprophylaxis, of which 497 patients $(11.0 \%)$ would develop a VTE [1]. In theory, a total of 616 VTEs would occur in our hospital annually, considering the guideline adherence in TO.

In T1, guideline adherence increased to $84.3 \%$. In this case, 8,367 of 9,925 patients with a high VTE risk would receive adequate thromboprophylaxis. Approximately 184 (2.2\%) of these patients would develop a VTE. Non-guideline adherence was 15.7\%; 1,558 patients with a high VTE risk would not have been treated with thromboprophylaxis, of which 171 (11.0\%) would develop a VTE. In theory, a total of 355 VTEs would occur in our hospital annually considering the guideline adherence in T1.

In conclusion, approximately 616 VTEs would occur annually without the multifaceted intervention and 355 VTEs would occur annually with all interventions in place. Therefore, the intervention potentially prevents 261 of $616(42.3 \%)$ VTEs every year.

\section{Discussion}


The multifaceted intervention significantly increased overall guideline adherence from $49.4 \%$ to $82.4 \%$, respectively. Also, in the patient group with a high VTE risk guideline adherence improved significantly from $54.5 \%$ to $84.3 \%$. Extrapolation of these results to an annual admission rate of 25,000 patients in our hospital, results in a potential decrease of \pm 261 (42.3\%) VTEs per year.

To our knowledge, this is the first study describing such a large effect on guideline adherence after the implementation of a multifaceted intervention. We believe this is mostly due to the highly specific and user-friendly design of our CDS. For example, the CDS is integrated in the EHR to ensure hospital wide availability. Also, the CDS has a highly specific 'focused' design to prevent alert fatigue; prescribers are only alerted if patients actually have a high VTE risk and are not treated with anticoagulant therapy. To achieve this level of specificity, the CDS design and build were based on (derivatives of) discrete data, a time consuming but worthwhile process that led to the immediate availability of the Padua Prediction Scores in the EHR. Additionally, thromboprophylaxis could be prescribed with a single click in order to make it easy for prescribers 'to do the right thing'.

Various studies have described that these characteristics are important factors for a successful CDS. For example, Eijgenraam et al. investigated the use of CDS, which was only available on a limited number of computers that were unable to communicate with the EHR [23]. Moreover, Kucher et al. investigated the effect of a multifaceted intervention, consisting of training for prescribers and a non-specific CDS in the form of continuously flashing non-interruptive alerts in the EHR when thromboprophylaxis was not ordered $[18,20]$ This intervention resulted in a moderate guideline adherence increase of $23 \%$. To our knowledge, no other study described the effect of a multifaceted intervention, with a highly-specific CDS incorporating the Padua Prediction Score in the EHR.

It is interesting to know which intervention has the most impact. The CDS seems to have a large effect in the post-intervention group. In March 2020, the month in which the post-intervention data collection took place, 2,100 patients were admitted, the CDS alert was shown to prescribers 1,144 times and was accepted 401 times (data not shown). This alone already leads to an increase of approximately $19 \%$ in compliance with guidelines.

In contrast to our expectations, the clinical rule 'duplicate anticoagulant medication' had little effect on the primary outcome measure. None of the enrolled patients in $\mathrm{T} 1$ had received an intervention based on the combination of thromboprophylaxis and therapeutic anticoagulation, while $16(18.8 \%)$ and 22 (25.9\%) patients were on therapeutic anticoagulation in T0 and T1, respectively. The effect of the phone application and training of prescribers is difficult to measure.

Our study has several limitations. Only non-surgical patients were included in this study, because the use of thromboprophylaxis is different between surgical and non-surgical patients. In our hospital, the perioperative anticoagulation policy is covered in electronic standardized ordersets readily available in the EHR and therefore would need a different approach to improve adherence [4]. Moreover, multiple studies have described that the administration of appropriate thromboprophylaxis in non-surgical patients is worse than in surgical patients [5,25-27]. 
The period between T0 and T1 was long (14 months), potentially resulting in the influence of factors outside our multifaceted intervention. This period was necessary for the various interventions to be built and implemented. In this time period, there were no changes in our guidelines for thromboprophylaxis, EHR usage, training or prescription policy on this topic in our hospital. We believe that the influence of factors, other than the ones described above, is small due to the broad, comprehensive design of the interventions. We do not expect that the time difference may explain the increase in guideline adherence. As described in several articles, the guideline adherence in TO is comparable with several international studies $[9,18,21-23,28]$.

The results of this study are dependent on the documentation in the EHR by practitioners in two ways: risk factors must be documented in the EHR, otherwise they could be missed in the data analysis of T0 and T1. In addition, risk factors such as active cancer, previous VTE and rheumatic disease must be documented in the so-called 'problem list' for the CDS to be able to include them. Otherwise, these risk factors are omitted in the calculated Padua Prediction Score. Numerous studies have described the incompleteness of patients' problem lists in hospitals, causing a lower effectiveness of CDS $[29,30]$.

Future study should address whether other hospitals will show the same results with this multifaceted intervention and if the increase in guideline adherence is sustained over time. Moreover, several studies have reported a $90 \%$ or more guideline adherence after the implementation of dedicated multidisciplinary teams [31,32]. Our multifaceted intervention, combined with the implementation of such a multidisciplinary team might further increase guideline adherence in a sustained matter and should be studied too [31,32].

\section{Conclusion}

A multifaceted intervention, including a highly specific CDS for high-risk VTE patients, has demonstrated to increase adherence to thromboprophylaxis guidelines significantly with $33 \%$. This potentially prevents 261 VTEs per year in our hospital.

\section{Declarations}

Acknowledgements: No acknowledgements to declare

Funding: This research did not receive any specific grant from funding agencies in the public, commercial, or not-for-profit sectors.

Conflicts of interest: No conflicts to declare

Availability of data and material: Not applicable

Code availability: Not applicable 
Authors' contributions: T. Jaspers contributed to study design, CDS design, training of prescribers, data collection, statistical analysis and writing the inital draft of the manuscript. M. Duisenberg-van Essenberg contributed to study design, CDS design and provided vital reviews of the manuscript. M. Durian contributed to CDS design and provided vital reviews of the manuscript. R. van den Berg contributed to study design, had a pivotal role in the CDS design and provided vital reviews of the manuscript. B. Maat contributed to study design, statistical analysis and provided vital reviews of the manuscript. P. van den Bemt contributed to study design, statistical analysis and provided vital reviews of the manuscript.

\section{References}

[1] Barbar S, Noventa F, Rossetto V, Ferrari A, Brandolin B, Perlati M, et al. A risk assessment model for the identification of hospitalized medical patients at risk for venous thromboembolism: the Padua Prediction Score. J Thromb Haemost 2010;8:2450-7.

[2] Janata K, Holzer M, Domanovits H, Mullner M, Bankier A, Kurtaran A, et al. Mortality of patients with pulmonary embolism. Wien Klin Wochenschr 2002;114:766-72.

[3] Duff J, Walker K, Omari A, Stratton C. Prevention of venous thromboembolism in hospitalized patients: analysis of reduced cost and improved clinical outcomes. J Vasc Nurs 2013;31:9-14.

[4] Beckman MG, Hooper WC, Critchley SE, Ortel TL. Venous thromboembolism: a public health concern. Am J Prev Med 2010;38:S495-501.

[5] Kahn SR, Lim W, Dunn AS, Cushman M, Dentali F, Akl EA, et al. Prevention of VTE in nonsurgical patients: Antithrombotic Therapy and Prevention of Thrombosis, 9th ed: American College of Chest Physicians Evidence-Based Clinical Practice Guidelines. Chest 2012;141:e195S-e226S.

[6] Huisman MV, Bakx R, Coppens M, Dijk EJ v, Dubois EA, Erven L v, et al. Richtlijn Antitrombotisch Beleid [Internet]. Dutch Internists Association (NIV). Utrecht. 2015. Available from:

https://internisten.nl/files/Richtlijn\%20Antitrombotisch\%20beleid_def.pdf. Accessed on 2021 Jan 28

[7] Rosenberg DJ, Press A, Fishbein J, Lesser M, McCullagh L, McGinn T, et al. External validation of the IMPROVE Bleeding Risk Assessment Model in medical patients. Thromb Haemost 2016;116:530-6.

[8] Cohen AT, Tapson VF, Bergmann JF, Goldhaber SZ, Kakkar AK, Deslandes B, et al. Venous thromboembolism risk and prophylaxis in the acute hospital care setting [ENDORSE study]: a multinational cross-sectional study. Lancet 2008;371:387-94.

[9] Moesker MJ, Damen NL, Groot JFd, Bruijne MCd, Wagner C. Antistollingszorg in Nederlandse ziekenhuizen. Evaluatie van tromboseprofylaxe en perioperatief antistollingsbeleid in vergelijking met geldende richtlijnen [Internet]. Utrecht/Amsterdam: NIVEL and EMGO+/VUmc; 2017. 73 p. ISBN 978-946122-445-3. 
https://www.nivel.nl/sites/default/files/bestanden/Antistollingszorg_nederlandse_ziekenhuizen.pdf. Accessed on 2021 Jan 28

[10] Kahn SR, Morrison DR, Cohen JM, Emed J, Tagalakis V, Roussin A, et al. Interventions for implementation of thromboprophylaxis in hospitalized medical and surgical patients at risk for venous thromboembolism. Cochrane Database Syst Rev 2013;7:CD008201.

[11] Kahn SR, Morrison DR, Diendere G, Piche A, Filion KB, Klil-Drori AJ, et al. Interventions for implementation of thromboprophylaxis in hospitalized patients at risk for venous thromboembolism. Cochrane Database Syst Rev 2018;4:CD008201.

[12] Dobesh PP, Stacy ZA. Effect of a clinical pharmacy education program on improvement in the quantity and quality of venous thromboembolism prophylaxis for medically ill patients. J Manag Care Pharm 2005;11:755-62.

[13] Stewart D, Zalamea N, Waxman K, Schuster R, Bozuk M. A prospective study of nurse and patient education on compliance with sequential compression devices. Am Surg 2006;72:921-3.

[14] Baskin C, Seetharamu N, Mazure B, Vassallo L, Steinberg H, Kerpen H, et al. Effect of a CD-ROMbased educational intervention on resident knowledge and adherence to deep venous thrombosis prophylaxis guidelines. J Hosp Med 2008;3:42-7.

[15] Boddi M, Barbani F, Abbate R, Bonizzoli M, Batacchi S, Lucente E, et al. Reduction in deep vein thrombosis incidence in intensive care after a clinician education program. J Thromb Haemost 2010;8:121-8.

[16] Pai M, Lloyd NS, Cheng J, Thabane L, Spencer FA, Cook DJ, et al. Strategies to enhance venous thromboprophylaxis in hospitalized medical patients [SENTRY]: a pilot cluster randomized trial. Implement Sci 2013;8:1.

[17] Roy PM, Rachas A, Meyer G, Le Gal G, Durieux P, El Kouri D, et al. Multifaceted Intervention to Prevent Venous Thromboembolism in Patients Hospitalized for Acute Medical Illness: A Multicenter ClusterRandomized Trial. PLoS One 2016;11:e0154832.

[18] Kucher N, Koo S, Quiroz R, Cooper JM, Paterno MD, Soukonnikov B, et al. Electronic alerts to prevent venous thromboembolism among hospitalized patients. N Engl J Med 2005;352:969-77.

[19] Overhage JM, Tierney WM, McDonald CJ. Computer reminders to implement preventive care guidelines for hospitalized patients. Arch Intern Med 1996;156:1551-6.

[20] Kucher N, Puck M, Blaser J, Bucklar G, Eschmann E, Luscher TF. Physician compliance with advanced electronic alerts for preventing venous thromboembolism among hospitalized medical patients. $J$ Thromb Haemost 2009;7:1291-6. 
[21] Umscheid CA, Hanish A, Chittams J, Weiner MG, Hecht TE. Effectiveness of a novel and scalable clinical decision support intervention to improve venous thromboembolism prophylaxis: a quasiexperimental study. BMC Med Inform Decis Mak 2012;12:92.

[22] Leal LF, Falavigna M, Gazzana MB, Maccari JG, Ghizzoni F, Alves D, et al. Protocol implementation for venous thromboembolism prophylaxis: a before-and-after study in medical and surgical patients. $J$ Bras Pneumol 2020;46:e20180325

[23] Eijgenraam P, Meertens N, van den Ham R, Ten Cate H, Ten Cate-Hoek AJ. The effect of clinical decision support on adherence to thrombosis prophylaxis guidelines in medical patients; a single center experience. Thromb Res 2015;135:464-71.

[24] Groenwold RH, Klungel $\mathrm{OH}$, Grobbee DE, Hoes AW. Selection of confounding variables should not be based on observed associations with exposure. Eur J Epidemiol 2011;26:589-93.

[25] Gould MK, Garcia DA, Wren SM, Karanicolas PJ, Arcelus JI, Heit JA, et al. Prevention of VTE in nonorthopedic surgical patients: Antithrombotic Therapy and Prevention of Thrombosis, 9th ed: American College of Chest Physicians Evidence-Based Clinical Practice Guidelines. Chest 2012;141:e227S-e277S.

[26] Monreal M, Kakkar AK, Caprini JA, Barba R, Uresandi F, Valle R, et al. The outcome after treatment of venous thromboembolism is different in surgical and acutely ill medical patients. Findings from the RIETE registry. J Thromb Haemost 2004;2:1892-8.

[27] Lecumberri R, Marques M, Panizo E, Alfonso A, Garcia-Mouriz A, Gil-Bazo I, et al. High incidence of venous thromboembolism despite electronic alerts for thromboprophylaxis in hospitalised cancer patients. Thromb Haemost 2013;110:184-90.

[28] Cohen AT, Tapson VF, Bergmann JF, Goldhaber SZ, Kakkar AK, Deslandes B, et al. Venous thromboembolism risk and prophylaxis in the acute hospital care setting [ENDORSE study]: a multinational cross-sectional study. Lancet 2008;371:387-94.

[29] Wright A, Pang J, Feblowitz JC, Maloney FL, Wilcox AR, McLoughlin KS, et al. Improving completeness of electronic problem lists through clinical decision support: a randomized, controlled trial. J Am Med Inform Assoc 2012;19:555-61.

[30] Wright A, McCoy AB, Hickman TT, Hilaire DS, Borbolla D, Bowes WA,3rd, et al. Problem list completeness in electronic health records: A multi-site study and assessment of success factors. Int $\mathrm{J}$ Med Inform 2015;84:784-90.

[31] Maynard G. Preventing hospital-associated venous thromboembolism: a guide for effective quality improvement [Internet]. Rockville, MD: Agency for Healthcare Research and Quality; 2008 Aug [Updated 2016 Aug]. 92 p. Report No.:16-0001-EF. Available from:

https://www.ahrq.gov/sites/default/files/publications/files/vteguide.pdf. Accessed on 2021 Jan 28. 
[32] Streiff MB, Carolan HT, Hobson DB, Kraus PS, Holzmueller CG, Demski R, et al. Lessons from the Johns Hopkins Multi-Disciplinary Venous Thromboembolism (VTE) Prevention Collaborative. Br Med J 2012;344:e3935.

[33] Chen HL, Cao YJ, Zhang W, Wang J, Huai BS. Braden scale (ALB) for assessing pressure ulcer risk in hospital patients: A validity and reliability study. Appl Nurs Res 2017;33:169-74.

\section{Tables}

Table 1: Overview of the intervention components [1,33].

\begin{tabular}{|c|c|c|}
\hline When & Component & Description \\
\hline $\begin{array}{l}\text { November } \\
2018\end{array}$ & $\begin{array}{l}\text { Mobile phone } \\
\text { application } \\
\text { 'Pocket } \\
\text { Cards' }\end{array}$ & $\begin{array}{l}\text { A decision support mobile phone application, based on the Padua } \\
\text { prediction score, could be consulted by the prescriber at any time to } \\
\text { decide whether to start thromboprophylaxis. Risk factors of a patient } \\
\text { must be entered manually in this application, with no link to the EHR. }\end{array}$ \\
\hline July 2019 & $\begin{array}{l}\text { Clinical rule } \\
\text { 'duplicate } \\
\text { anticoagulant } \\
\text { medication' }\end{array}$ & $\begin{array}{l}\text { A patient list in the EHR, automatically selecting patients with } \\
\text { combinations of thromboprophylaxis (ATC code B01AB) and } \\
\text { therapeutic anticoagulation (ATC codes B01AA, B01AE and B01AF), } \\
\text { was assessed daily by a pharmacist for rationale of combinations of } \\
\text { anticoagulants. In the event of an incorrect combination, the } \\
\text { pharmacist advised the prescriber to discontinue thromboprophylaxis. }\end{array}$ \\
\hline $\begin{array}{l}\text { December } \\
2019\end{array}$ & Training & $\begin{array}{l}\text { Training of prescribers on the wards neurology, internal medicine and } \\
\text { oncology \& hematology, covering the incidence of VTEs in non-surgical } \\
\text { patients, the effect of thromboprophylaxis on the incidence of VTEs } \\
\text { and the results of the control group data collection. A demonstration } \\
\text { of CDS, which would be implemented in February 2020, was given. }\end{array}$ \\
\hline $\begin{array}{l}\text { February } \\
2020\end{array}$ & CDS & $\begin{array}{l}\text { An advanced CDS, aggregating data from the EHR, gave an automated } \\
\text { advice to the physician in the EHR whether thromboprophylaxis was } \\
\text { necessary according to the Padua prediction score. To this end, the } \\
\text { CDS collects data from the patients' problem list (e.g. malignancy, VTE } \\
\text { in the past, thrombophilia), patient characteristics (sex, age, weight, } \\
\text { BMI), the medication list (hormonal treatment and anticoagulants) and } \\
\text { from the mobility score of the Braden score (mobility), which is } \\
\text { assessed for each patient in our hospital within } 24 \text { hours after } \\
\text { admission [1,33]. If the Padua score is } \geq 4 \text { and no anticoagulant is in } \\
\text { use, the CDS generates an advice (pop-up) to the prescriber to initiate } \\
\text { medicinal thromboproophylaxis. This advice is adapted to the weight } \\
\text { and BMI of the patient; an order for dalteparin } 2,500 \text { IE is suggested in } \\
\text { patients }<90 \text { kg and BMI <30kg / m2, otherwise dalteparin } 5,000 \text { IE is } \\
\text { suggested. Because the bleeding risk is not included in the CDS, a } \\
\text { general disclaimer is included that the prescriber must consider the } \\
\text { bleeding risk. }\end{array}$ \\
\hline
\end{tabular}

EHR = Electronic health record; ATC = Anatomical Therapeutic Chemical; VTE = venous thromboembolism; CDS = Clinical Decision Support 
Table 2: Padua Prediction Score and Improve Bleeding risk assessment tool $[1,7]$.

\begin{tabular}{|c|c|c|c|}
\hline \multirow{2}{*}{\multicolumn{2}{|c|}{$\begin{array}{l}\text { Padua Prediction Score } \\
\text { High risk of VTE: } \geq 4\end{array}$}} & \multicolumn{2}{|l|}{ Improve Bleeding Risk } \\
\hline & & \multicolumn{2}{|c|}{$\begin{array}{l}\text { High risk of bleeding: } \geq 7, \text { or } \geq 1 \text { of the high-risk factors prior } \\
\text { bleeding }(<3 \text { months), active gastric or duodenal ulcer or platelet } \\
\text { count less than } 50 \times 10^{9} / \mathrm{L}\end{array}$} \\
\hline Risk factor & Score & Risk factor & Score \\
\hline Active cancer ${ }^{\mathrm{a}}$ & 3 & Moderate renal failure (eGFR $30-50 \mathrm{ml} / \mathrm{min}$ ) & 1 \\
\hline Previous VTE ${ }^{b}$ & 3 & Male sex & 1 \\
\hline Reduced mobility ${ }^{\mathrm{c}}$ & 3 & $40-84$ years & 1.5 \\
\hline $\begin{array}{l}\text { Thrombophilic } \\
\text { conditiond }^{d}\end{array}$ & 3 & Active cancer & 2 \\
\hline $\begin{array}{l}\text { Recent ( } \leq 1 \text { month }) \\
\text { trama and/or } \\
\text { surgery }\end{array}$ & 2 & Rheumatic disease & 2 \\
\hline Age ( $\geq 70$ years) & 1 & Central venous catheter & 2 \\
\hline $\begin{array}{l}\text { Heart and/or } \\
\text { respiratory failure }\end{array}$ & 1 & Admission in Intensive Care Unit & 2.5 \\
\hline $\begin{array}{l}\text { Acute Ml or } \\
\text { ischemic stroke }\end{array}$ & 1 & Sever renal failure (<30 ml/min) & 2.5 \\
\hline $\begin{array}{l}\text { Acute infection } \\
\text { and/or } \\
\text { rheumatologic } \\
\text { disorder }\end{array}$ & 1 & Liver insufficiency (INR > 1.5) & 2.5 \\
\hline $\mathrm{BMI} \geq 30 \mathrm{~kg} / \mathrm{m} 2$ & 1 & $\geq 85$ years & 3.5 \\
\hline \multirow[t]{3}{*}{ Hormonal treatment } & 1 & Thrombocytopenia $\left(<50 \times 10^{9} \mathrm{cell} / \mathrm{L}\right)$ & 4 \\
\hline & & Recent ( $<3$ months) bleeding & 4 \\
\hline & & Active gastro-intestinal ulcer & 4.5 \\
\hline
\end{tabular}

$\mathrm{VTE}$ = venous thromboembolism; $\mathrm{MI}=$ myocardial infarction; $\mathrm{BMI}=$ Body Mass Index; eGFR = estimated Glomerular Filtration Rate; INR = International Normalized Ratio ·

aPatients with local or distant metastases and/or in whom chemotherapy or radiotherapy had been

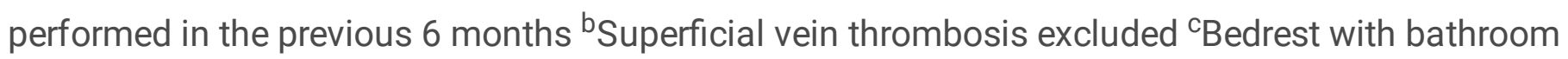
privileges [either due to patient's limitations or on physicians order] for at least 3 days ${ }^{\mathrm{d}}$ Carriage of defects of antithrombin, protein C or S, factor V Leiden, G20210A prothrombin mutation, antiphospholipid syndrome. 
Table 3: Patient characteristics

Page 15/19 


\begin{tabular}{|c|c|c|c|}
\hline Variable & TO [n=85] & $\mathrm{T} 1[\mathrm{n}=85]$ & P-value \\
\hline \multicolumn{4}{|l|}{ Patient characteristics } \\
\hline Male sex, n [\%] & $49[57.6]$ & $52[61.2]$ & 0.64 \\
\hline Age, mean years $\pm S D$ & $65.8 \pm 16.9$ & $66.0 \pm 16.8$ & 0.95 \\
\hline Length of stay, median days \pm SD & $8.3 \pm 8.6$ & $7.4 \pm 5.1$ & 0.41 \\
\hline Weight, mean $\mathrm{kg} \pm \mathrm{SD}$ & $77.8 \pm 17.4$ & $76.6 \pm 17.6$ & 0.67 \\
\hline BMI, mean $\mathrm{kg} / \mathrm{m}^{2} \pm \mathrm{SD}$ & $26.1 \pm 5.0$ & $26.2 \pm 5.5$ & 0.92 \\
\hline Therapeutic anticoagulation in use, $\mathrm{n}$ [\%] & 16 [18.8] & $22[25.9]$ & 0.27 \\
\hline High risk of VTEa, $\mathrm{n}[\%]$ & $65[76.5]$ & $60[70.6]$ & 0.39 \\
\hline High risk of bleeding ${ }^{b}, \mathrm{n}[\%]$ & 13 [15.3] & $12[14.1]$ & 0.83 \\
\hline High VTE and bleeding risk, n [\%] & 10 [11.8] & 9 [10.6] & 0.81 \\
\hline High VTE risk, without risk of bleeding, $\mathrm{n}$ [\%] & $55[64.7]$ & $51[60.0]$ & 0.53 \\
\hline Department, n [\%] & & & 0.17 \\
\hline Internal Medicine & $34[40.0]$ & 24 [28.2] & - \\
\hline Neurology & 29 [34.1] & 29 [34.1] & - \\
\hline Oncology \& haematology & $22[25.9]$ & $32[37.6]$ & - \\
\hline \multicolumn{4}{|l|}{ Risk factors for VTE, n [\%] } \\
\hline Active cancer & $26[30.6]$ & 28 [32.9] & 0.74 \\
\hline Previous VTE & 15 [17.6] & $12[14.1]$ & 0.53 \\
\hline Reduced mobility & $55[64.7]$ & $50[58.8]$ & 0.43 \\
\hline Trombophilic condition & $0[0.0]$ & $1[1.2]$ & 1.00 \\
\hline Recent ( $\leq 1$ month) trauma and/or surgery & $7[8.2]$ & $7[8.2]$ & 1.00 \\
\hline Age ( $\geq 70$ years) & $41[48.2]$ & $44[51.8]$ & 0.65 \\
\hline Heart and/or respiratory failure & 27 [31.8] & 28 [32.9] & 0.87 \\
\hline Acute MI or ischemic stroke & 14 [16.5] & $17[20.0]$ & 0.55 \\
\hline Acute infection & 30 [35.3] & 33 [38.8] & 0.63 \\
\hline Rheumatic disease & 28 [32.9] & 24 [28.2] & 0.51 \\
\hline $\mathrm{BMI} \geq 30 \mathrm{~kg} / \mathrm{m} 2$ & $17[20.0]$ & $17[20.0]$ & 1.00 \\
\hline Hormonal treatment & $2[2.4]$ & $0[0.0]$ & 0.49 \\
\hline
\end{tabular}




\begin{tabular}{|llll|}
\hline Padua score, mean \pm SD & $5.4 \pm 2.8$ & $5.3 \pm 3.1$ & 0.86 \\
\hline Risk factors for bleeding, $\mathbf{n}$ [\%] & & & 0.57 \\
\hline Age category & & & - \\
\hline 0 - 39 years & $8[9.4]$ & $7[8.2]$ & - \\
\hline $40-84$ years & $66[77.6]$ & $71[83.5]$ & - \\
\hline$\geq 85$ years & $11[12.9]$ & $7[8.2]$ & - \\
\hline Renal failure $(e G F R<50 \mathrm{ml} / \mathrm{min})$ & $17[20.0]$ & $19[22.4]$ & 0.71 \\
\hline Active cancer & $26[30.6]$ & $28[32.9]$ & 0.74 \\
\hline Rheumatic disease & $28[32.9]$ & $24[28.2]$ & 0.51 \\
\hline Central Venous catheter & $9[10.6]$ & $7[8.2]$ & 0.60 \\
\hline Hepatic failure $(\mathrm{INR}>1,5)$ & $2[2.4]$ & $3[3.5]$ & 1.00 \\
\hline Platelet count $<50 \times 10^{9}$ cells $/ \mathrm{I}$ & $1[1.2]$ & $3[3.5]$ & 0.62 \\
\hline Recent bleeding $(\leq 3$ months) & $7[8.2]$ & $8[9.4]$ & 0.79 \\
\hline Active gastroduodenal ulcer & $2[2.4]$ & $2[2.4]$ & 1.00 \\
\hline Improve bleed score, mean $\pm S D$ & $4.3 \pm 2.4$ & $4.3 \pm 2.5$ & 0.82 \\
\hline
\end{tabular}

$\mathrm{T} 0$ = pre-intervention measurement; $\mathrm{T} 1$ = post-intervention measurement; $\mathrm{SD}=$ standard deviation; $\mathrm{VTE}=$ venous thromboembolism; $\mathrm{MI}$ = myocardial infarction; $\mathrm{BMI}=$ Body Mass Index; $\mathrm{eGFR}$ = estimated Glomerular Filtration Rate; INR = International Normalized Ratio.

aPadua score $\geq 4$, ${ }^{b}$ Improve score $\geq 7$, or $\geq 1$ of the high-risk factors prior bleeding in the last 3 months, active gastric or duodenal ulcer or platelet count less than $50 \times 10^{9} / \mathrm{L}$.

Table 4: Adherence to thromboprophylaxis guidelines before (T0) and after (T1) intervention.

\begin{tabular}{|c|c|c|c|c|}
\hline Classification of treatment & $\begin{array}{l}\text { T0 } \\
{[n=85]}\end{array}$ & $\begin{array}{l}\text { T1 } \\
{[n=85]}\end{array}$ & $\mathrm{OR}[95 \% \mathrm{Cl}]$ & $\begin{array}{l}\text { Adjusted OR } \\
{[95 \% \mathrm{Cl}]^{\mathrm{a}}}\end{array}$ \\
\hline Overall guideline adherence, $\mathrm{n}$ [\%] & $\begin{array}{l}42 \\
{[49.4]}\end{array}$ & $\begin{array}{l}70 \\
{[82.4]}\end{array}$ & $\begin{array}{l}4.78[2.37- \\
9.63]^{*}\end{array}$ & $\begin{array}{l}5.88[2.74- \\
12.62]^{*}\end{array}$ \\
\hline $\begin{array}{l}\text { Thromboprophylaxis according to } \\
\text { guidelines }\end{array}$ & $\begin{array}{l}17 \\
{[20.0]}\end{array}$ & $\begin{array}{l}30 \\
{[35.3]}\end{array}$ & $\begin{array}{l}2.18[1.09- \\
4.36]^{\star}\end{array}$ & $\begin{array}{l}2.56[1.21- \\
5.42]^{\star}\end{array}$ \\
\hline $\begin{array}{l}\text { No thromboprophylaxis according to } \\
\text { guidelines }\end{array}$ & $\begin{array}{l}25 \\
{[29.4]}\end{array}$ & $\begin{array}{l}40 \\
{[47.1]}\end{array}$ & $\begin{array}{l}2.13[1.13- \\
4.01]^{*}\end{array}$ & $\begin{array}{l}2.59[1.21- \\
5.58]^{\star}\end{array}$ \\
\hline
\end{tabular}


$\mathrm{T} 0$ = pre-intervention measurement; $\mathrm{T} 1$ = post-intervention measurement; $\mathrm{OR}=$ Odds Ratio, $\mathrm{Cl}=$ Confidence interval. * Statistically significant $(95 \% \mathrm{Cl}>1.00)$

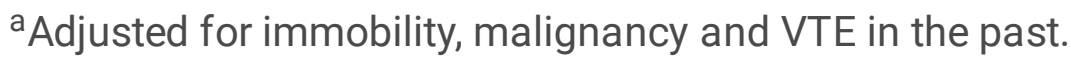

\section{Figures}

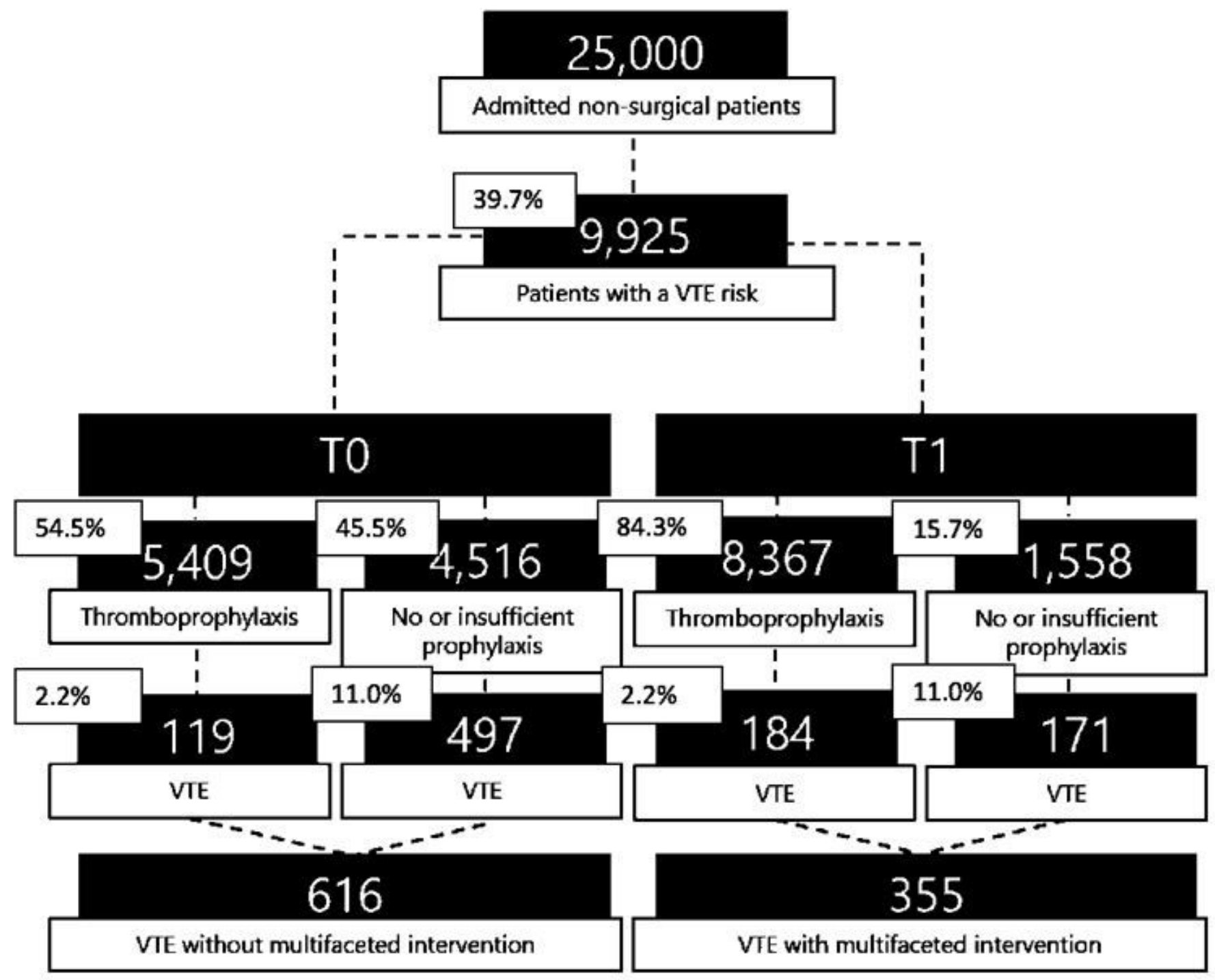

$\mathrm{VTE}=$ venous thromboembolism; $\mathrm{T} 0=$ pre-intervention measurement; $\mathrm{T} 1=$ post-intervention measurement. The percentage of adherence and non-adherence to guidelines in T0 and T1 is extrapolated to the total number of patients with a high VTE risk $(9,925)$. Subsequently, a VTE incidence of $2.2 \%$ is considered in the population receiving adequate thromboprophylaxis, compared to $11.0 \%$ in the population receiving no or inadequate thromboprophylaxis.

Figure 1 
The number of venous thromboembolisms in pre- and post-intervention measurement, extrapolated to the annual number of admitted patients in the ETZ 